\title{
The Utility of Cervical Spine Bracing As a Postoperative Adjunct to Multilevel Anterior Cervical Spine Surgery
}

\author{
IAN F. CAPLAN, BS, ${ }^{1}$ SAURABH SINHA, MD ${ }^{1}$ BENJAMIN OSIEMO, $\mathrm{MS},{ }^{2,3}$ SCOTT D. MCCLINTOCK, \\ PHD,${ }^{3}$ JAMES M. SCHUSTER, MD, PHD,${ }^{1}$ HARVEY SMITH, MD,${ }^{4}$ GREGORY GLAUSER, BS, ${ }^{1}$ NIKHIL \\ SHARMA, BS, ${ }^{1}$ ALI K. OZTURK, MD,${ }^{1}$ ZARINA S. ALI, MD, ${ }^{1}$ NEIL R. MALHOTRA, MD ${ }^{1,5}$ \\ ${ }^{1}$ University of Pennsylvania Perelman School of Medicine, Department of Neurosurgery, Philadelphia, Pennsylvania, ${ }^{2}$ McKenna EpiLog Fellowship in Population \\ Health at the University of Pennsylvania, Philadelphia, Pennsylvania, ${ }^{3}$ West Chester University, Department of Mathematics and West Chester Statistical \\ Institute, West Chester, Pennsylvania, ${ }^{4}$ University of Pennsylvania Perelman School of Medicine, Department of Orthopedic Surgery, Philadelphia, Pennsylvania, \\ ${ }^{5}$ Translational Spine Research Lab of the University of Pennsylvania, Philadelphia, Pennsylvania
}

\begin{abstract}
Background: Use of cervical bracing/collar subsequent to anterior cervical spine discectomy and fusion (ACDF) is variable. Outcomes data regarding bracing after ACDF are limited. Here, we study the impact of bracing on shortterm outcomes related to safety, quality of care, and direct costs in multilevel ACDF.

Methods: Retrospective cohort analyses of all consecutive patients undergoing multilevel ACDF with or without bracing from 2013 to 2017 was undertaken $(n=616)$. Patient demographics and comorbidities were analyzed. Tests of independence and logistic regressions were used to assess differences in length of stay (LOS), discharge disposition (home, assisted rehabilitation facility [ARF], or skilled nursing facility [SNF]), quality-adjusted life year (QALY), direct cost, readmission within 30 days, and emergency room (ER) visits within 30 days.

Results: Amongst the study population, 553 were braced and 63 were not braced. There was no difference in comorbidities $(P>.05)$ such as obesity, smoking, chronic obstructive pulmonary disease, hypertension, coronary artery disease, congestive heart failure, and problem list number. A significant difference in American Society of Anesthesiologists (ASA) score was found, with more ASA 2 patients in the braced cohort and more ASA 3 patients in the unbraced cohort $(P=.007)$. LOS was extended for the unbraced group (median $156.9 \pm 211.4$ versus $86.67 \pm$ $130.6 \mathrm{~h}, P=.003)$, and ER visits within 30 days were 0.21 times less likely in the braced group $(P=.006)$. There was no difference in readmission $(P=.181)$, QALY gain $(P=.968)$, and direct costs $(P=.689)$.
\end{abstract}

Conclusion: Bracing following multilevel cervical fixation does not alter short-term postoperative course or reduce the risk for early adverse outcomes in a significant manner.

Cervical Spine

Keywords: multilevel bracing, cervical fixation, anterior cervical discectomy and fusion (ACDF)

\section{INTRODUCTION}

Approximately 132,000 anterior cervical discectomy and fusions (ACDFs) are performed annually in the United States. ${ }^{1}$ ACDF is indicated and validated for a wide range of pathologies such as radiculopathy, myelopathy, degenerative disc disease, and degenerative spondylolysis to achieve decompression and fusion with significant improvement in patient outcomes, ${ }^{2-11}$ but the use of postoperative bracing following surgery remains contentious. A survey of spine surgeons illustrated the significant variability in postoperative practices by showing more surgeons brace after multilevel $\mathrm{ACDF}$ in comparison to single-level ACDF. ${ }^{12}$

Current investigations into the impact of bracing on outcomes in multilevel ACDF reveal mixed results. Rates of pseudarthrosis and perioperative complications have been reported to be increased after multilevel ACDF in comparison to single-level $\mathrm{ACDF}$ in part due to distribution of force on a larger construct, ${ }^{13,14}$ and the use of bracing has been thought to improve outcomes for the multilevel cases. ${ }^{15-17}$ Supporters thus argue that cervical braces decrease pressure and axial load on the construct thereby improving fusion rates. Critics of bracing believe that the internal fixation afforded by an ACDF obviates any requirement for external bracing. ${ }^{18,19}$ Biomechanical analyses of cervical braces are also mixed. Some evidence suggests bracing leads to a change in gait affecting patient quality of life and safety, ${ }^{20-22}$ whereas other studies report no change in balance when wearing a cervical brace. $^{23}$ Cervical braces are also associated with 
pressure ulcers, ${ }^{24}$ dysphagia, ${ }^{25}$ respiratory compromise, ${ }^{26}$ and restriction of range of motion. ${ }^{27-29}$

Therefore, mixed consensus exists regarding bracing after multilevel ACDF, with studies supporting short-term bracing ${ }^{30}$ and others showing no difference in outcomes. ${ }^{31,32} \mathrm{We}$ have shown in a previous study that bracing after single-level ACDF shows no difference in outcomes. ${ }^{33}$ In this study, we sought to expand upon our prior result by evaluating short-term outcomes and associated direct costs related to cervical bracing following multilevel ACDF.

\section{MATERIALS AND METHODS}

\section{Study Population}

In this Institutional Review Board (IRB) approved study, patients undergoing multilevel ACDF surgical intervention across a university health system were enrolled retrospectively from July 1, 2013, to June 30, 2017. A waiver of informed consent was granted by the IRB as this study was considered to be minimal risk to patients. Retrospective cohort analysis was performed using the Neurosurgery Quality Improvement Initiative (NQII) EpiLog tool and resulted in 616 consecutive patients who underwent multilevel ACDF during the study period. Briefly, the NQII EpiLog tool is a nonproprietary clinical research and quality improvement architecture that was built and overlaid onto the electronic health record system, which enables prospective data collection.

Our study population included patients undergoing multilevel ACDF performed by 20 neurosurgeons. The population was separated into braced and unbraced cohorts. All acute trauma cases were excluded from the study and remaining cases were limited to electively scheduled cases. Intraoperative technique and instrumentation used was at each surgeon's discretion, although instrumentation is consistent across the health system due to long-term purchasing agreements.

\section{Data Collection}

Patient data were collected via the NQII EpiLog tool from the electronic health record. Patient age, gender, race, American Society of Anesthesiologists (ASA) score that rates perfect health as 1 and moribund as 5, and comorbidities such as diabetes, chronic obstructive pulmonary disease (COPD), and coronary artery disease (CAD), congestive
Table 1. Patient demographics and comorbidities.

\begin{tabular}{|c|c|c|c|}
\hline Variable & $\begin{array}{l}\text { Brace, } \\
\text { n }(\%)\end{array}$ & $\begin{array}{c}\text { No Brace, } \\
\text { n }(\%)\end{array}$ & $P$ Value \\
\hline Sex & & & .3628 \\
\hline Male & 265 (47.92) & $34(53.97)$ & \\
\hline Female & $288(52.08)$ & $29(46.03)$ & \\
\hline Diabetes & $20(3.96)$ & $5(8.93)$ & .0874 \\
\hline COPD & $3(0.59)$ & $0(0.0)$ & 1.0000 \\
\hline CAD & $4(0.79)$ & $1(1.79)$ & .4101 \\
\hline Obesity & $8(1.58)$ & $2(3.57)$ & .2628 \\
\hline $\mathrm{CHF}$ & $1(0.20)$ & $0(0.0)$ & 1.0000 \\
\hline Hypertension & $61(12.08)$ & $10(17.86)$ & .2173 \\
\hline Smoker & $114(21.07)$ & $15(25.42)$ & .4369 \\
\hline Race & & & .0861 \\
\hline Asian & $5(0.90)$ & $2(3.17)$ & \\
\hline Black & $74(13.38)$ & $14(22.22)$ & \\
\hline White & $436(78.84)$ & $42(66.67)$ & \\
\hline Hispanic/Latino & $12(2.17)$ & $1(1.59)$ & \\
\hline Unknown & $15(2.71)$ & $2(3.17)$ & \\
\hline Other & $9(1.63)$ & $1(1.59)$ & \\
\hline Pacific Island & $0(0.0)$ & $0(0.0)$ & \\
\hline East Indian & $2(0.36)$ & $1(1.59)$ & \\
\hline ASA Grade & & & .0066 \\
\hline ASA 1 & $17(3.09)$ & $0(0.0)$ & \\
\hline ASA 2 & $341(62.0)$ & $30(47.62)$ & \\
\hline ASA 3 & $190(34.55)$ & $31(49.21)$ & \\
\hline ASA 4 & $2(0.36)$ & $2(3.17)$ & \\
\hline Graft type & & & $<.0001$ \\
\hline Allograft & $270(48.82)$ & $55(87.30)$ & \\
\hline Autograft & $240(43.40)$ & $2(3.17)$ & \\
\hline Biomechanical & $5(0.90)$ & $0(0.0)$ & \\
\hline Allograft + autograft & $1(0.18)$ & $0(0.0)$ & \\
\hline $\begin{array}{l}\text { Autograft }+ \\
\text { biomechanical }\end{array}$ & $13(2.35)$ & $0(0.0)$ & \\
\hline $\begin{array}{l}\text { Allograft }+ \\
\text { biomechanical }\end{array}$ & $3(0.54)$ & $0(0.0)$ & \\
\hline \multirow[t]{2}{*}{ None } & $21(3.80)$ & $6(9.52)$ & \\
\hline & Mean \pm SD & Mean \pm SD & \\
\hline Pack years & $19.18 \pm 14.35$ & $15.31 \pm 14.52$ & .3118 \\
\hline $\begin{array}{l}\text { Total number of } \\
\text { comorbidities }\end{array}$ & $4.95 \pm 6.10$ & $5.92 \pm 5.88$ & .1402 \\
\hline BMI & $28.77 \pm 6.12$ & $27.37 \pm 5.10$ & .0835 \\
\hline Duration of follow-up & $210.9 \pm 234.2$ & $287.7 \pm 237.7$ & .3364 \\
\hline Age & $54.56 \pm 11.16$ & $58.06 \pm 12.82$ & .0204 \\
\hline
\end{tabular}

Abbreviations: ASA, American Society of Anesthesiologists; BMI, body mass index; CAD, coronary artery disease; CHF, congestive heart failure; COPD, chronic obstructive pulmonary disease.

heart failure (CHF), hypertension, smoking status, pack years, graft type, duration of follow-up, body mass index (BMI), and total number of comorbidities at the time of index surgery were recorded (Table 1). Indicators of outcome were recorded and included increased length of stay (LOS) (Table 2), discharge disposition, emergency room (ER) visit within 30 days, and readmission within 30 days (Figure 1). In a small consecutive prospective pilot, 104 braced and 8 unbraced patients (from the total of 616 patients) completed the EQ-5D-3L questionnaire, a validated measure of health outcomes for cost-utility analysis, to calculate quality-adjusted life years (QALYs). Total cost was calculated as all 
Table 2. Comparison of quality and cost of care.

\begin{tabular}{lccc}
\hline & Brace, Mean \pm SD & No Brace, Mean \pm SD & $\boldsymbol{P}$ Value \\
\hline LOS & $86.67 \pm 130.6$ & $156.9 \pm 211.4$ & .0025 \\
Total cost & $4321.6 \pm 3811.9$ & $3438.0 \pm 1726.9$ & .6887 \\
QALY & $0.0307 \pm 0.1030$ & $0.0550 \pm 0.1133$ & .9684 \\
\hline
\end{tabular}

Abbreviations: LOS, length of stay; QALY, quality-adjusted life year; SD,

standard deviation.

actual costs directly incurred by the hospital, retrieved from billing databases (Table 2).

\section{Statistical Methods}

All continuous variables were assessed with the Student $t$ test or Wilcoxon Rank Sum test where appropriate. All categorical variables were analyzed with Pearson $\chi^{2}$ test or Fisher exact test. Multinomial logistic regression analyses were used to determine disposition location based on independent variable of bracing. Significant results were defined as $P<.05$. Averages are presented as mean \pm standard deviation.

\section{RESULTS}

\section{Patient Demographics}

The retrospective cohort analysis consisted of patients who underwent multilevel ACDF $(n=616)$, where 553 patients were braced and 63 were not braced (Table 1). There were no gender differences between the braced and unbraced cohorts $(P=$ .363). Braced patients were younger than those who were unbraced $(54.56 \pm 11.16$ versus $58.06 \pm 12.82$ $\mathrm{y}, P=.020)$. There were no differences in race $(P=$ .086), or comorbidities including diabetes, COPD, CAD, obesity, smoking, total number of comorbidities, or BMI. However, there were significant differences in the overall physical status of patients as defined by the ASA score with more ASA 2 patients in the braced cohort and more ASA 3 patients in the unbraced cohort $(P=.007)$. Amongst the study population, there was a difference in graft type with braced patients more frequently receiving autografts and those unbraced receiving allografts $(P<.0001)$.

\section{Safety of Care}

The postoperative course differed to some degree between the 2 groups. LOS was extended for the unbraced group compared with the braced group $(156.9 \pm 211.4$ versus $86.67 \pm 130.6 \mathrm{~h}, P=.003)$. Patients who were braced were 2.68 times more

\section{Multilevel ACDF 30 Day Outcomes}

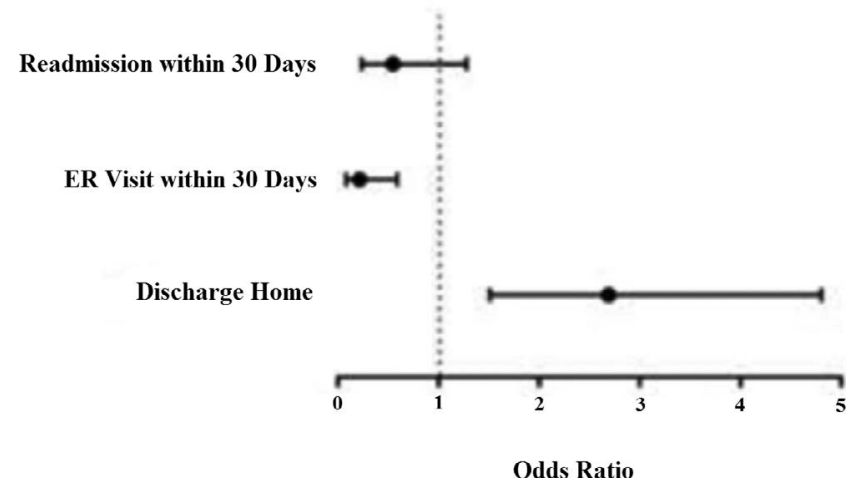

Figure 1. Short-term postoperative risk assessment. Depiction of odds ratios for short-term outcomes following multilevel ACDF. The braced cohort was compared with the nonbrace cohort in reference to 30-day readmission, ER visits, and discharge to home or to SNF/ARF. Abbreviations: ACDF, anterior cervical spine discectomy and fusion; ARF, assisted rehabilitation facility; ER, emergency room; SNF, skilled nursing facility.

likely to be discharged home, compared with an assisted rehabilitation facility (ARF) or a skilled nursing facility (SNF), than those patients who were unbraced $(P=.0006$, confidence interval $[\mathrm{CI}]=$ 1.501-4.792). ER visits within 30 days were 0.21 times less likely in the braced patients in comparison with those not braced $(P=.006, \mathrm{CI}=0.076-0.583$ ). There was no difference in readmissions within 30 days between the 2 cohorts $(P=.181)$ seen in Figure 1 .

\section{Quality and Cost-Effectiveness}

Patient QALY gain was no different between the 2 groups $(P=.968)$. Assessment of total costs also showed no difference between bracing and not bracing patients following ACDF $(P=.689$; Table 2).

\section{DISCUSSION}

In this study, unbraced patients had a reduced likelihood of a home discharge, increased LOS, and increased likelihood of an ER visit within 30 days but no difference in 30-day readmissions. Further, there were no differences in hospital cost or patientdescribed quality of life. The original description of ACDF in Smith and Robinson's ${ }^{34}$ paper from 1958 noted that postoperative bracing was generally limited to multilevel ACDF. Internal instrumentation has undergone significant developments since this report; as such, one may expect a decrease in the use of bracing due to the known restriction of neck motion after multilevel fusion. ${ }^{35}$ The paucity of 
decisive literature has made it challenging to make an informed decision about bracing in the setting of multilevel ACDF.

There are a few recent studies aimed to address postoperative bracing. In a previous investigation, our group showed no difference in benefit for postoperative bracing following single-level ACDF. ${ }^{33}$ Abbott et $\mathrm{al}^{30}$ show a benefit of bracing after ACDF in their study population that included both single and 2-level ACDF. A meta-analysis from Zhu et $\mathrm{al}^{36}$ found that there was no support for postoperative bracing following a number of spine surgeries including ACDF, posterior lumbar arthrodesis, thoracic posterior decompression and fusion, and cervical laminoplasty as measured by patient-reported efficacy, radiographic outcomes, safety, and cost-effectiveness. Unfortunately, the literature still lacks studies that clearly delineate multilevel ACDF from single-level in a broader sample population. Previous studies used narrower study populations, but that does not reflect variability in surgical practice that may affect clinical outcomes. $^{37}$

Although postoperative bracing is not indicated in every setting, the data here suggest it may have a role in postoperative care for selected cases. There is some evidence to argue that internal instability remains in the postoperative setting because cervical motion is detectable 2 weeks after ACDF independent of the number of levels fused. ${ }^{38}$ Furthermore, the detrimental effects of smoking on bone health and healing ${ }^{39}$ leads to lower fusion rates, increased rates of pseudarthrosis, and overall worse outcomes for patients who smoke. ${ }^{40-43}$ The decision to brace may thus be better approached from an individualized perspective with consideration of specific comorbidities and corresponding likelihood of complications for a given patient.

From the current study, it is difficult to draw definitive conclusions. With regard to short-term outcomes, the braced patients were 2.68 times more likely to be discharged home and 0.21 times less likely to be in the ER within 30 days of surgery. These findings in conjunction with an increased LOS for those patients who were not braced may indicate that there is some hazard to not bracing following a multilevel ACDF. Interestingly, despite increased LOS in the unbraced cohort, neither the total cost to the hospital nor the QALY gains were different between the 2 cohorts. LOS is known to be a major predictor of cost in $\mathrm{ACDF},{ }^{44}$ but it is not correlated with the total cost data related to the study population here. Furthermore, despite increased likelihood of discharge to SNF/ARF along with increased likelihood of ER visits, the unbraced cohort expressed equivalent improvements in quality of life at 8.8 months. The lack of difference in cost, QALY gains, and the rate of 30-day readmissions contribute to the uncertainty of these results and suggest that nonbracing may be reasonable in some settings.

The cost of cervical braces, which are not included in the total cost calculation presented here, ranges from $\$ 25$ to $\$ 750 .{ }^{45}$ By removing this cost from patients and insurers while providing equivalent results, the removal of postoperative bracing could be the highest value care provided to patients with ACDF. ${ }^{46}$ To verify this, future prospective analysis with a balanced population size is necessary to determine whether foregoing a brace is a safe and effective option.

This study aimed to assess the efficacy of bracing in a broad and heterogeneous multilevel ACDF population. The study population was constructed such that surgeon-specific practices of strictly bracing or not bracing patients following multilevel ACDF removed bias of patient selection, which was confirmed in the similarity between the 2 cohorts. All patients received anterior plating, but graft type was not controlled for and showed significant differences between the 2 cohorts. Further, there were important differences between cohorts, with more ASA 2 patients in the braced cohort and more ASA 3 patients in the unbraced cohort. Nevertheless, there was no difference in 30day readmissions between the 2 groups. This analysis was not powered to determine if differences in graft-type or surgical choice generated differential short-term outcomes in these patients, but again this study intended to include variability in patient presentation and surgical practice in order to generalize results to all elective multilevel ACDF cases.

This study is limited by its retrospective cohort design despite the use of the prospective data gathering NQII EpiLog tool. Recording bias is a potential problem with the retrospective design and cannot be avoided. To this end, we report data as means and standard deviations without removing outliers to prevent selection bias. All patients included in the study are reflective of the spectrum 
of complexity in ACDF cases seen at this institution. There is a limited number of patients with QALY gains data, which results in a small sample size for this metric, but it was a planned secondary measure within the study design to act as a confirmatory measure. In future prospective studies, a focus on gathering QALY data will be able to confirm these results. In this study, we assess the early impact of bracing, however, we do not assess long-term pseudarthrosis rates. It will be important to assess for presence of spinal fusion in long-term analysis.

Due to the imbalance in sample size between the 2 cohorts, the authors were unable to analyze the data set with the strictest statistical measures. The univariate analyses reported above are representative of the relationship between bracing and patient outcomes but are not able to incorporate preoperative variables in the analysis. We aim to expand the population to generate a propensity score-matched trial design to further control for the differing demographic variables. Further equivocal results would suggest the value of a prospective randomized control trial.

The results of this study are inconclusive on the short-term use of bracing following multilevel ACDF, however, the data suggest that major markers of negative outcome (hospital readmission, postoperative health care related quality of life) are comparable with or without bracing. The use of postoperative bracing remains a common practice, and the data reported here do not clearly indicate its need or absence thereof, despite reduced LOS and increased home disposition. These mixed results warrant future prospective investigations to delineate if there are true differences in short-term outcomes with cervical bracing following ACDF, as well as long-term studies that assess patientreported outcome measures, fusion rates, and reoperation rates.

\section{ACKNOWLEDGMENTS}

This research received no specific grant from any funding agency in the public or commercial sectors. Support was received from the Kevin and Bernadette McKenna Family Research Fund.

This study was approved by the Institutional Review Board (IRB) at the Hospital of the University of Pennsylvania. IRB number for this study is: 825280 . A waiver of informed consent was granted by the University of Pennsylvania IRB as this study was considered to be minimal risk to patients. All ethical guidelines and rules were followed to protect patient privacy.

NRM and IFC were involved in the design and conception of this manuscript. IFC performed the literature review and compiled the primary manuscript. NRM, BO, and SDM collected and analyzed data. IFC compiled the figures and tables. NRM, IFC, JMS, HS, BO, ZA, NS, GG, and AO critically revised the manuscript. All authors approved the manuscript as it is written.

\section{REFERENCES}

1. Saifi C, Fein AW, Cazzulino A, et al. Trends in resource utilization and rate of cervical disc arthroplasty and anterior cervical discectomy and fusion throughout the United States from 2006 to 2013. Spine J. 2018;18(6):1022-1029.

2. Park Y, Maeda T, Cho W, et al. Comparison of anterior cervical fusion after two-level discectomy or single-level corpectomy: sagittal alignment, cervical lordosis, graft collapse, and adjacent-level ossification. Spine J. 2010;10(3):193199.

3. Marbacher S, Hidalgo-Staub T, Kienzler J, et al. Longterm outcome after adjacent two-level anterior cervical discectomy and fusion using stand-alone plasmaphore-covered titanium cages. J Neurol Surg A Cent Eur Neurosurg. 2015;76(3):199-204.

4. Wang JC, McDonough PW, Endow KK, et al. Increased fusion rates with cervical plating for two-level anterior cervical discectomy and fusion. Spine (Phila Pa 1976). 2000;25(1):4145 .

5. Wang JC, McDonough PW, Endow K, et al. The effect of cervical plating on single-level anterior cervical discectomy and fusion. J Spinal Disord. 1999;12(6):467-471.

6. Wang JC, McDonough PW, Kanim LE, et al. Increased fusion rates with cervical plating for three-level anterior cervical discectomy and fusion. Spine (Phila Pa 1976). 2001;26(6):643646; discussion 646-647.

7. Kaiser MG, Haid RW Jr, Subach BR, et al. Anterior cervical plating enhances arthrodesis after discectomy and fusion with cortical allograft. Neurosurgery. 2002;50(2):229236; discussion 236-238.

8. Kang L, Lin D, Ding Z, et al. Artificial disk replacement combined with midlevel ACDF versus multilevel fusion for cervical disk disease involving 3 levels. Orthopedics. 2013;36(1):e88-e94.

9. Xu L, Sun H, Li Z, et al. Anterior cervical discectomy and fusion versus posterior laminoplasty for multilevel cervical myelopathy: a meta-analysis. Int $J$ Surg. 2017;48:247-253.

10. Wen ZQ, Du JY, Ling ZH, et al. Anterior cervical discectomy and fusion versus anterior cervical corpectomy and fusion in the treatment of multilevel cervical spondylotic myelopathy: systematic review and a meta-analysis. Ther Clin Risk Manag. 2015;11:161-170.

11. He S, Feng $\mathrm{H}$, Lan $\mathrm{Z}$, et al. A randomized trial comparing clinical outcomes between zero-profile and tradi- 
tional multilevel anterior cervical discectomy and fusion surgery for cervical myelopathy. Spine (Phila Pa 1976). 2018;43(5):E259-E266.

12. Bible JE, Biswas D, Whang PG, et al. Postoperative bracing after spine surgery for degenerative conditions: a questionnaire study. Spine J. 2009;9(4):309-316.

13. Lee DH, Cho JH, Hwang CJ, et al. What is the fate of pseudarthrosis detected 1 year after anterior cervical discectomy and fusion? Spine (Phila Pa 1976). 2018;43(1):E23-E28.

14. Veeravagu A, Cole T, Jiang B, et al. Revision rates and complication incidence in single- and multilevel anterior cervical discectomy and fusion procedures: an administrative database study. Spine J. 2014;14(7):1125-1131.

15. Schneider AM, Hipp JA, Nguyen L, et al. Reduction in head and intervertebral motion provided by 7 contemporary cervical orthoses in 45 individuals. Spine (Phila Pa 1976). 2007;32(1):E1-E6.

16. Zhang S, Wortley M, Clowers K, et al. Evaluation of efficacy and 3D kinematic characteristics of cervical orthoses. Clin Biomech (Bristol, Avon). 2005;20(3):264-269.

17. Quintana LM. Complications in anterior cervical discectomy and fusion for cervical degenerative disc disease. World Neurosurg. 2014;82(6):1058-1059.

18. Connolly PJ, Grob D. Bracing of patients after fusion for degenerative problems of the lumbar spine-yes or no? Spine (Phila Pa 1976). 1998;23(12):1426-1428.

19. Bhowmick DA, Benzel EC. Cervical orthoses after atlantoaxial fixation: who are we treating, the patient or ourselves? World Neurosurg. 2013;79(2):271-272.

20. Russell DM, Kelleran KJ, Morrison S. Bracing the trunk and neck in young adults leads to a more aged-like gait. Gait Posture. 2016;49:388-393.

21. Morrison S, Russell DM, Kelleran K, et al. Bracing of the trunk and neck has a differential effect on head control during gait. J Neurophysiol. 2015;114(3):1773-1783.

22. Karlberg M, Magnusson M, Johansson R. Effects of restrained cervical mobility on voluntary eye movements and postural control. Acta Otolaryngol. 1991;111(4):664-670.

23. Burl MM, Williams JG, Nayak US. Effects of cervical collars on standing balance. Arch Phys Med Rehabil. 1992;73(12):1181-1185.

24. Webber-Jones JE, Thomas CA, Bordeaux RE Jr. The management and prevention of rigid cervical collar complications. Orthop Nurs. 2002;21(4):19-25; quiz 25-27.

25. Stambolis V, Brady S, Klos D, et al. The effects of cervical bracing upon swallowing in young, normal, healthy volunteers. Dysphagia. 2003;18(1):39-45.

26. Totten VY, Sugarman DB. Respiratory effects of spinal immobilization. Prehosp Emerg Care. 1999;3(4):347-352.

27. Sandler AJ, Dvorak J, Humke T, et al. The effectiveness of various cervical orthoses. An in vivo comparison of the mechanical stability provided by several widely used models. Spine (Phila Pa 1976). 1996;21(14):1624-1629.

28. Johnson RM, Hart DL, Simmons EF, et al. Cervical orthoses. A study comparing their effectiveness in restricting cervical motion in normal subjects. J Bone Joint Surg Am. 1977;59(3):332-339.

29. Gao F. Effectiveness of adjustable cervical orthoses and modular cervical thoracic orthoses in restricting neck motion: a comparative in vivo biomechanical study. Spine (Phila $\mathrm{Pa}$ 1976). 2015;40(19):E1046-E1051.
30. Abbott A, Halvorsen M, Dedering A. Is there a need for cervical collar usage post anterior cervical decompression and fusion using interbody cages? A randomized controlled pilot trial. Physiother Theory Pract. 2013;29(4):290-300.

31. Elliott RE, Tanweer O, Boah A, et al. Is external cervical orthotic bracing necessary after posterior atlantoaxial fusion with modern instrumentation: meta-analysis and review of literature. World Neurosurg. 2013;79(2):369-74.e1-12.

32. Overley SC, Merrill RK, Baird EO, et al. Is cervical bracing necessary after one- and two-level instrumented anterior cervical discectomy and fusion? A prospective randomized study. Global Spine J. 2018;8(1):40-46.

33. Caplan IF, Sinha S, Schuster JM, et al. The utility of cervical spine bracing as a postoperative adjunct to single-level anterior cervical spine surgery. Asian J Neurosurg. 2019;14:461466.

34. Smith GW, Robinson RA. The treatment of certain cervical-spine disorders by anterior removal of the intervertebral disc and interbody fusion. J Bone Joint Surg Am. 1958;40A(3):607-624.

35. Wu XD, Wang XW, Yuan W, et al. The effect of multilevel anterior cervical fusion on neck motion. Eur Spine J. 2012;21(7):1368-1373.

36. Zhu MP, Tetreault LA, Sorefan-Mangou F, et al. Efficacy, safety, and economics of bracing after spine surgery: a systematic review of the literature. Spine J. 2018;18(9):15131525.

37. Nunley PD, Jawahar A, Kerr EJ 3rd, et al. Choice of plate may affect outcomes for single versus multilevel ACDF: results of a prospective randomized single-blind trial. Spine $J$. 2009;9(2):121-127.

38. Mourning D, Reitman CA, Heggeness MH, et al. Initial intervertebral stability after anterior cervical discectomy and fusion with plating. Spine J. 2007;7(6):643-646.

39. Yan C, Avadhani NG, Iqbal J. The effects of smoke carcinogens on bone. Curr Osteoporos Rep. 2011;9(4):202209.

40. Hilibrand AS, Fye MA, Emery SE, et al. Impact of smoking on the outcome of anterior cervical arthrodesis with interbody or strut-grafting. J Bone Joint Surg Am. 2001;83A(5):668-673.

41. Kusin DJ, Ahn UM, Ahn NU. The effect of smoking on spinal cord healing following surgical treatment of cervical myelopathy. Spine (Phila Pa 1976). 2015;40(18):1391-1396.

42. Tetreault LA, Cote P, Kopjar B, et al. A clinical prediction model to assess surgical outcome in patients with cervical spondylotic myelopathy: internal and external validations using the prospective multicenter AOSpine North American and international datasets of 743 patients. Spine J. 2015;15(3):388-397.

43. Lau D, Chou D, Ziewacz JE, et al. The effects of smoking on perioperative outcomes and pseudarthrosis following anterior cervical corpectomy: clinical article. J Neurosurg Spine. 2014;21(4):547-558.

44. Reese JC, Karsy M, Twitchell S, et al. Analysis of anterior cervical discectomy and fusion healthcare costs via the value-driven outcomes tool. Neurosurgery. 2019;84(2):485-490.

45. Agabegi SS, Asghar FA, Herkowitz HN. Spinal orthoses. J Am Acad Orthop Surg. 2010;18(11):657-667.

46. Porter ME. What is value in health care? $N$ Engl J Med. 2010;363(26):2477-2481. 
Disclosures and COI: The authors have no disclosures to report.

Corresponding Author: Neil R. Malhotra, MD, Perelman School of Medicine at the University of Pennsylvania, Department of Neurosurgery, 3rd Floor Silverstein Pavilion, 3400 Spruce St
Published 30 April 2020

This manuscript is generously published free of charge by ISASS, the International Society for the Advancement of Spine Surgery. Copyright (C) 2020 ISASS. To see more or order reprints or permissions, see http://ijssurgery.com. 